\title{
O conflito de representações inter-étnicas em torno da exploração de diamantes na Amazônia brasileira
}

\author{
The conflict of interethinic relations in the Brazilian Amazon diamond mining
}

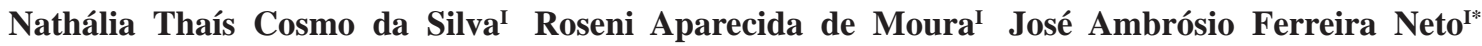

RESUMO

Este artigo analisa o documentário Jewel of Amazon, produzido por jornalistas norte-americanos, sobre a realidade do Grupo Indígena Cinta Larga, especificamente os conflitos que envolvem esse grupo em torno da exploração dos diamantes presentes em suas terras no município de Espigão D`Oeste, em Rondônia. Busca-se sobretudo analisar o estigma atribuído às sociedades indígenas pela população local em virtude da exploração indiscriminada de recursos naturais que vinham ocorrendo na reserva.

Palavras-chave: conflito, relações inter-étnicas, estigma, fronteiras.

\section{ABSTRACT}

This article aims to analyze the documentary Jewel of Amazon, produced by American journalists about the reality of indigenous group Cinta Larga, specifically the conflicts involving this group around the exploration of diamonds present in their lands of which location is in the city Espigão D'Oeste”, in Rondonia's state. The documentary content points to issues that involve both the entry of non-Indians in the lands mentioned beforeand the stigma attached to indigenous societies by the local population due to the indiscriminate exploration of natural resources that occurred in the reserve.

Key words: conflict, stigma, interethnic relations, frontier.

\section{INTRODUÇÃO}

Este trabalho é fruto das discussões desenvolvidas pelo grupo de pesquisa “Assentamentos” em relação ao atual processo de desenvolvimento na Amazônia. Objetivamente, em relação à questão indígena, os estudos empíricos se desenvolvem em Rondônia, tangendo a necessidade de entender os inúmeros processos econômicos que os povos indígenas vivenciam na região amazônica, os quais, por sua vez, desencadeiam uma série de transformações de ordem social, cultural e ambiental. Além de pesquisas empíricas, o grupo se dedica ao mapeamento da realidade indígena no estado através de análises documentais, o que inclusive resultou na proposta de artigo.

Ao se propor analisar as representações construídas acerca dos índios Cinta Larga e do esteoreótipo estabelecido em relação aos garimpeiros faz-se necessário uma breve incursão histórica da realidade a partir da descoberta dos diamantes na Reserva Roosevelt ,principalmente, considerando os conflitos que daí se alargaram.

No sudoeste da Amazônia, os Cinta Larga ocupam territórios entre os estados de Rondônia e Mato Grosso, havendo indícios de que a exploração ilícita dos recursos ambientais e minerais nas Terras Indígenas (TI`s) da etnia Cinta Larga ocorre desde a década de 1940. Desde então, as ininterruptas atividades exploratórias oscilavam entre a atividade madeireira clandestina e formas predatórias de garimpo. Para este artigo, importa o recorte das questões inerentes a TI Roosevelt, uma vez que ali, a partir de 1999, deu-se a descoberta de uma grande jazida de diamantes, o que acarretou na intensificação da presença de garimpeiros, empresas de mineração e sucessivos conflitos.

'Departamento de Economia Rural, Universidade Federal de Viçosa (UFV), Campus da UFV, 36570-000, Viçosa, MG, Brasil. E-mail:ambrosio@ufv.br.*Autor para correspondência. 
Pesquisadores norte-americanos que se interessaram pelo caso Cinta Larga no auge da repercussão do embate entre índios e garimpeiros em 2004 - que culminou na morte de 29 representantes destes últimos -, publicaram, na revista eletrônica FRONTLINE (2006), o documentário Jewel of the Amazon. O objetivo desse documentário era relatar os estudos sobre os povos indígenas da Amazônia, tendo como destaque os Cinta Larga da Reserva Roosevelt. Assim, os esforços em torno dessa publicação se concentraram em responder ao questionamento feito no subtítulo "Quem controlará aquela que pode vir a ser a mais rica mina de diamantes no mundo?”

Jewel Of Amazon, cuja tradução para a língua portuguesa é “Jóia da Amazônia”, é um documentário completo sobre a descoberta da jazida de diamantes na Reserva Roosevelt, pertencente ao grupo indígena Cinta Larga, e dos conflitos que daí se alargaram. Os jornalistas Darren Foster e Mariana Van Zeller estiveram na aldeia e fizeram uma coleta de dados com os atores sociais do conflito. Disso resultou uma gama de dados e informações publicadas da revista online FRONTLINE, os quais se pretende analisar neste artigo. Chamava atenção dos jornalistas a riqueza material obtida pelos Cinta Larga em decorrência do garimpo, uma vez que são vistos em carros luxuosos, utilizam telefones móveis via satélite e se casam fora da tribo, o que contesta a visão da maioria das pessoas - não índios - de como um grupo indígena deveria se comportar.

Nessa conjuntura, a dinâmica socioeconômica e cultural entre os Cinta Larga e a população local, entre aqueles e os garimpeiros, bem como as representações construídas nessas relações trazem para o debate a análise das peculiaridades dos Cinta Larga, no que tange ao encontro inter-cultural de índios e não índios e os conflitos que envolvem essa relação, contribuindo para o aprofundamento das discussões referentes à estigmatização, às representações e ao imaginário social em relação a determinadas categorias.

Num primeiro momento, será feita uma breve discussão sobre os conceitos de representação, imaginário e estigma; no momento seguinte, esta se concentrará no imaginário dos jornalistas, suas impressões e estranhamentos quando estiveram em contato com o cenário do conflito e, por fim, serão contrapostas as diferentes visões dos atores sociais do conflito, com o propósito de realizar um balanço entre o que permeia o imaginário destes.

\section{Um balanço teórico}

As proposições de GOFFMAN (1982) sobre estigma se constituem na principal base da análise do conflito, bem como os seus desdobramentos relacionais entre indígenas, população local e garimpeiros. Tal conceito é definido como uma situação em que o indivíduo não está apto a ser aceito plenamente na sociedade, percebendo-se então que, entre a população da área do conflito e os índios Cinta Larga, há um processo de estigmatização em que são considerados assassinos - pela morte dos 29 garimpeiros em 2004.

O conceito de estigma pressupõe os “contatos mistos”, que são momentos em que os estigmatizados e os "normais" estão na mesma situação social, na qual é a própria sociedade que estabelece os meios de categorizar os indivíduos, bem como de eleger os atributos a serem considerados comuns e naturais para os membros de cada uma dessas categorias sociais.

Nesse sentido, existiria uma série características às quais os grupos indígenas deveriam se encaixar. Isso porque, com base em pré-concepções, são criadas expectativas normativas e exigências que deverão ser apresentadas rigorosamente através das categorias de indivíduos, seus atributos e sua identidade social, de modo que o desvirtuamento de tais características resulta no estigma.

Em relação ao universo indígena, existe uma tendência em classificar a relação dos índios com os objetos oriundos da sociedade industrial capitalista ou a realização de atividades econômicas como fenômenos inautênticos ou até mesmo inaceitáveis. Nesse contexto, atributos indesejáveis se relacionam com as atividades indígenas dissonantes daquelas respaldadas pela sociedade, como a caça, a pesca, a coleta e tudo mais que remete à vida natural e primitiva. Isso pode ser também explicado pela contribuição argumentativa de GOFFMAN (1980), no sentido de que os diferentes papéis atribuídos socialmente têm relação com a forma como indivíduos idealizam sua imagem, principalmente considerando a relação que aflora entre os pares.

Noutras palavras, a construção do bom selvagem é capaz de provocar um choque aos que encontram, na realidade, índios munidos de aparatos tecnológicos e tendo anseios que coadunam com a lógica capitalista de reprodução dos meios de vida.

As discussões de Goffman, instrumentalizadas em relação aos desdobramentos do conflito envolvendo os Cinta Larga, vem acompanhadas, neste trabalho, também pelas análises de BARTH (1998) sobre as fronteiras entre os grupos. O aspecto harmônico entre os dois autores se dá pelo entendimento de que as ações dos sujeitos são interpretadas por diferentes atores sociais através 
de distintas perspectivas, de modo que a circulação entre fronteiras é marcada por relações complexas e contraditórias, mas que não acarretam na perda de identidade, uma vez que está é dinâmica.

Os estudos de BARTH (1998) também dialogam com as clássicas análises sobre relações inter-étnicas de OLIVEIRA (1974) no sentido de defender a sobrevivência do fator étnico, apesar das fronteiras entre os grupos.

Além disso, o conflito é analisado, paralelamente à análise de GOFFMAN (1980), pela perspectiva dos dramas sociais, trazida por TURNER (1974), que, seguindo essa linha de observar o teatro da vida, se interessa pelos momentos em que os papéis estão suspensos, o meta teatro da vida social. Para o autor, que se atém às transformações da sociedade, o conflito se configura por um drama social, com impactos nas estruturas sociais, capazes de criar antiestruturas, que, por sua vez, podem ser capazes de revitalizar tecidos sociais.

Finalmente, para analisar os discursos polarizados dos atores sociais em conflito, também são importantes as proposições de BACZKO (1985), que realizou uma análise em que o imaginário social está diretamente relacionado às questões de poder. A pertinência das considerações de BACZKO (1985) para o problema aqui tratado diz respeito à conformação do conflito no qual se dá uma disputa, não só pela exploração dos diamantes na Reserva Roosevelt, mas também pela legitimização dos discursos dos atores sociais envolvidos no conflito, com vistas às decisões do Estado em relação ao futuro da reserva, dos índios e dos garimpeiros. "Um rude despertar para o mundo moderno": impressões e estranhamentos dos jornalistas.

A intensificação da relação dos Cinta Larga com os não índios se dá pela exploração do diamante, que parece resultar num movimento dos índios em direção às perspectivas econômicas sob a lógica dos brancos em relação à mercantilização dos diamantes e à (re) significação desse elemento em sua cultura.

Interessante é perceber o processo pelo qual passaram os jornalistas. Um processo de desconstrução da imagem estereotipada do índio e das representações que se fazem deste enquanto pertencente a uma comunidade tradicional. No imaginário dos jornalistas, permeava ainda a ideia dos índios nus, correndo pela floresta, sendo restrito à selva sem contato direto com a população. Contudo, a percepção do real se chocou com o imaginado, já que o observado foram índios dirigindo carros, com um contato estreito com não índios, possuindo ainda casas na cidade, bem como telefonia via satélite.
O estranhamento desses jornalistas residia no fato de os índios possuírem carros luxuosos, casas agradáveis na cidade e até se casarem fora da tribo, o que se contrapunha com o esperado isolamento, vida rudimentar, mais associada à natureza e sem muitos bens.

Para eles, essa modernização dos índios Cinta Larga, a intensificação do contato com não índios e a própria lógica exploratória se caracterizava por "um rude despertar para o mundo moderno". Isso porque os conflitos entre índios, garimpeiros e população se acirraram, formando pólos antagônicos em relação ao futuro da mina e a uma disputa pela legitimização dos atores sociais que terão direito a explorá-la.

Por outro lado, o que os jornalistas observaram sobre as impressões da população local a respeito dos índios Cinta larga é que estes são vistos como assassinos impunes, e a falta de punição representa um desprezo pela vida dos garimpeiros e, sobretudo, uma injustiça. Além disso, na percepção da população local, o grupo Cinta larga é recompensado pelo governo, ou seja, existe uma proteção por parte da esfera governamental, por meio da Operação Roosevelt da Polícia Federal, aos grupos indígenas.

Segundo os relatos coletados para a organização do documentário, na época do incidente, aflorou um senso de injustiça muito forte entre a população local, sob o argumento de que os Cinta Larga estavam escapando, literalmente, da culpa do assassinato e que havia uma desvalorização em relação à vida dos garimpeiros mortos.

Pairam então, na organização cognitiva da população local, vários questionamentos quem têm como pano de fundo certa revolta, como observado no documentário ao realizar o questionamento a respeito do que teria acontecido se fossem 29 índios assassinados, o que na opinião da população local seria considerado um incidente de proporções internacionais.

Outra consideração que se pode fazer em relação às impressões dos jornalistas se refere ao tom da narrativa. No documento, alguns trechos expunham o quanto o assassinato dos garimpeiros havia sido cruel e se dado com o disparo de múltiplas balas, de modo que os corpos dos garimpeiros estavam irreconhecíveis. Nessa passagem, subentende-se que os jornalistas esperavam que o ataque se desse de outra forma. No mínimo, de uma forma mais rudimentar, com flechas talvez, porque, se assim fosse, haveria uma correspondência com a categoria indígena, segundo a representação que possuíam de tal grupo antes do contato direto ter sido realizado. $\mathrm{O}$ estranhamento reside no fato de o instrumento 
utilizado pelos índios obedecer a uma lógica não indígena de violência na concepção do olhar de fora.

Assim, a representação de um indígena que os jornalistas apresentavam antes de realizarem as entrevistas foi mudando, à medida que novos elementos de caracterização foram sendo incorporados a esta, em virtude de estarem lidando com um grupo imerso em um contexto que não estava "previsto" em seus esquemas cognitivos.

Imbuídos pelo interesse de saber da realidade dos garimpeiros, dada a magnitude do que encontraram no período em que permaneceram na localidade do conflito, puderam então entender o que caracterizava um garimpeiro, bem como as suas motivações. Ao entrevistarem um dos garimpeiros, entenderam que, ao contrário da maioria, este não tinha os atributos que esperavam para caracterizálo como tal. Já os garimpeiros, por outro lado, são vistos como tendo a vida desregrada, sem muita oportunidade. O garimpeiro entrevistado, na concepção dos jornalistas, não se caracterizava como garimpeiro, em virtude de seus atributos, uma vez que este foi considerado como bem-educado e se tornou garimpeiro por opção e não por falta de oportunidade, como acontece com os demais, contrapondo não só a representação que estes tinham de um garimpeiro, mas uma representação estigmatizada.

Ao analisar o discurso apresentado pelos jornalistas no documentário, percebeu-se que, em relação a ambos os casos, quais sejam, os dos índios e dos garimpeiros, foi desconstruída a imagem préconcebida desses atores sociais em conflito.

As relações interétnicas

Para facilitar o entendimento sobre o lugar que os índios Cinta Larga ocupam no imaginário da população local, faz-se necessário analisar a fronteira entre grupos sustentada por BARTH (1998), como delimitadoras das posições de grupos ou indivíduos nas diversas relações, mas também entendê-la como o locus da contradição em que se percebem interesses opostos e realidades sociais em ritmos diferentes. Assim, a polarização dos interesses entre garimpeiros e indígenas e a estigmatização dos indígenas pela população local demonstram a complexidade desse cenário de múltiplos atores com lógicas distintas

A partir da compreensão da identidade étnica como sendo dinâmica e passível de transformações através de relações, interesses ou contextos, BARTH (1998) lança mão da fronteira para entender a dinâmica dos grupos, cujas interações entre sujeitos podem gerar transformações que modelam a identidade. Assim, o compartilhamento de características confere aos grupos a capacidade de organização, na qual se define o "eu” e o "outro". A fronteira é ao mesmo tempo uma forma de categorizar o que está inclusive em sintonia com as proposições de GOFFMAN (1982), mas também pressupõe a interação entre os indivíduos.

Considerando a possibilidade das transformações de identidade, a partir da interação entre diferentes atores, neste caso acirrada a partir da descoberta do recurso mineral e do conflito, o próprio diamante já existente na Terra Indígena e portanto há algum tempo presente no universo de significados dos Cinta Larga, a partir do evento da sua exploração com fins econômicos, passa por um processo de (re) significação, no qual esse grupo indígena organiza sua inteligência e cria mecanismos de mudança que faz com que queiram também explorar o recurso natural ou se beneficiar economicamente de tal exploração. Aliás, o despertar dos interesses econômicos faz parte também do movimento da identidade indígena em conformidade com a lógica do mundo externo.

No entanto, é justamente a falta de clareza em relação à autenticidade dessa construção e desconstrução, ou seja, dessa dinamicidade, preconizada por BARTH (1998), da identidade indígena a fonte geradora do processo de estigmatização, pois se classifica idealmente que o índio deve ser selvagem, rude e isolado do mundo moderno. Quando a correspondência não ocorre, a tendência é estigmatizar e reduzir o indivíduo a uma pessoa estragada e diminuída, como aponta FERREIRA NETO \& DOULA (2003).

Os clássicos estudos de Roberto Cardoso de OLIVEIRA sobre fricções inter-étnicas já apontavam para um distanciamento do que foi convencionado denominar de aculturação. Isso porque, na opinião do estudioso, as entidades étnicas resistem às transformações culturais e raciais, à língua, aos costumes e às crenças, pois são características externas à etnia. Para além das especificidades culturais e raciais, as etnias seriam, de acordo com OLIVEIRA (1972), categorias compostas de representações recíprocas e de lealdades morais, de modo que a cultura não seria um desígnio do grupo étnico, mas produto dele.

BARTH (1998) e OLIVEIRA (1972) se comunicam no sentido de que as fronteiras sociais dos grupos não implicam a sua inexistência, não são capazes de rematar a cultura, mas esta, tal qual a identidade, é algo dinâmico e passível de reelaborações.

Desse modo, o movimento desse grupo indígena em relação à lógica exploratória e ao 
mundo dos bens fez com que fossem estigmatizados, pela população local, como índios capitalistas, preguiçosos, acomodados por usufruírem da riqueza da mina de diamantes ou da situação, já que essa riqueza concedia aos índios certos privilégios como recompensas financeiras concedidas pelos garimpeiros para que estes pudessem adentrar a reserva e explorar a jazida. O estigma nessa situação advém da não correspondência entre o índio como um nativo de florestas, isolado do mundo, e o movimento ao mundo movido pela produção em massa e pelo consumismo.

No entanto, tanto a contribuição de BARTH (1998) quanto a de OLIVEIRA (1972) demonstram a autenticidade das transformações ocorridas na sociedade Cinta Larga após o conflito. Tais mudanças não descaracterizam os Cinta Larga em relação à sua condição indígena e étnica, apenas evidenciam as transformações que se dão através das fronteiras entre grupos.

Vale observar, contudo, que, com o assassinato dos 29 garimpeiros em 2004, iniciouse um novo processo de estigmatização, uma vez que, segundo a população local, se os índios já não se comportam conforme sua identidade social, não seria justo que estes não fossem punidos pelo assassinato. Nessa perspectiva, os índios passam a ser privilegiados pelo Estado sob a justificativa de sua condição de indígena ou relativamente incapazes. Categoria esta que, na concepção da população local, já não corresponde ao pré-estabelecido.

Essa questão pode também ser analisada pela perspectiva dos “dramas sociais”, sustentado por TURNER (1974), que se atém aos ritos e dramas que passam as sociedades em decorrência das transformações sociais, políticas e culturais.

Para o estudioso, é possível que surjam na vida social os dramas que demarcam uma dialética entre a estrutura e antiestrutura. Isso quer dizer que, a partir das estruturas, que são um conjunto de relações empiricamente observáveis, que representa a vida cotidiana, podem emergir vez ou outra tensões ou elementos não resolvidos da vida social, que por sua vez configuram a antiestrutura, momentos em que os dramas sociais se afloram extraordinariamente. A antiestrutura como locus dos dramas sociais configura-se pela liminaridade, conceito utilizado pelo autor para remeter às transformações que se dão em virtude das próprias contradições, conflitos e crises, que podem inclusive romper as bases da estrutura social.

$\mathrm{Na}$ estrutura social estabelecida entre população indígena e população local, é possível observar algumas disposições e organizações de posições e atores que elas implicam. O conflito emerge então nos interstícios dessa estrutura social em que os indivíduos não mais correspondem aos atributos pré-definidos e transitam de um status ou lugar para outro na vida social, ou seja, transitam entre dois mundos.

Se por um lado as coisas de branco, como bens capitalistas, passam a fazer parte da vida social da aldeia. Por outro, na cidade (Cacoal), é possível encontrar casas, carros e motos pertencentes aos indígenas. Além disso, os últimos passam a ser consumidores do mercado local, a dialogar com a sociedade envolvente através dos códigos dos não índios, o que fica clarificado pelo interesse dos indígenas em explorar o recurso mineral.

Assim, o conflito entre Cinta Larga e população local culmina no processo de liminaridade. Isso ocorre por criar uma possibilidade dos grupos representarem, mesmo que simbolicamente, papéis que correspondem a uma posição invertida, em relação ao status ou condição que ordinariamente possuem no quadro hierárquico da estrutura social, ou seja, a vida indígena não se reduz ao selvagem, ao primitivo, à vida na aldeia. A partir do conflito, ela passa a tanger a possibilidade de que os indígenas ocupem lugar na vida cotidiana das cidades, a possibilidade também de que eles possam se beneficiar da atividade econômica em torno da exploração da jazida de diamantes. Finalmente, é válido observar que essa antiestrutura propiciada pelo conflito não configura necessariamente a ausência de estrutura, mas um modelo alternativo de organização social que emerge nas fendas da sociedade.

"Se você passar perto de uma colméia, as abelhas não farão nada a você, mas se você tentar levar algo de dentro dela, elas o atacarão": atores sociais do conflito.

Através das entrevistas contidas no documentário e realizadas com os atores sociais do conflito - Representante do Grupo Indígena Cinta Larga, da FUNAI, da Associação de Garimpeiros e da Polícia Federal -, foi possível extrair diferentes discursos que denotam uma luta pelo poder de explorar a mina ou de opinar sobre quem deverá explorá-la.

Tais discursos demonstram certas contradições entre os atores, bem como seus posicionamentos. O discurso de cada ator social é fortemente marcado pelos interesses das instituições ou pelas causas que representam. É nesse sentido que as discussões acerca do imaginário social alcançam pertinência, uma vez que este se torna inteligível e 
comunicável através da produção dos discursos, nos quais e pelos quais se efetua a reunião das representações coletivas numa linguagem (BACZKO, 1985).

Esta pode ser considerada uma questão de "poder", por se tratar de um jogo de relações entre grupos sociais com interesses distintos. Nessa perspectiva, as contribuições de BACKZO (1985) são conexas quando este defende que o imaginário social é uma peça efetiva e eficaz dos dispositivos de controle da vida coletiva, do exercício, sobretudo de autoridade e poder. Ao mesmo tempo, ele torna-se o "lugar e o objeto” dos conflitos sociais (BACZKO, 1985)

Mediante o anseio de explorar a jazida de diamantes, é possível perceber, na fala do chefe Pio, um desejo indígena pelo tratamento diferenciado enquanto categoria social diferente das demais. Essa assertiva fica evidenciada quando o chefe afirma, sobre os efeitos da exploração de diamante no cotidiano os indígenas Cinta Larga, que "por um lado, melhorou, por outro ficou pior, porque a vida se tornou mais estressante. Hoje, eu posso ver o lado negativo da mina - pessoas que perderam seus casamentos, alguns membros estão separados, as mulheres vão para a cidade. Esse foi o lado ruim. O lado positivo e onde a mina tem beneficiado a comunidade é a construção de casas bem construídas, estradas, projetos agrícolas, e ele trouxe o gado. Acho que o tratamento tem que ser diferenciado. Somos índios, de modo que então devemos ser tratados de forma diferente do homem branco. Então, hoje, nós temos um sistema de saúde diferente, diferentes sistemas de ensino, porque nem todos sabem falar português” (FRONTLINE, 2006).

Nesse caso, a representação dos indígenas de si próprios aponta para uma alteridade, uma vez que é através do "tratamento diferenciado" que se dá o reconhecimento social e a forma de angariar benefícios junto às instituições governamentais. O discurso da liderança indígena está em sintonia com os argumentos de GOFFMAN (1980) sobre a possibilidade de uma reação em relação à estigmatização, ou seja, a essas noções pré-atribuídas, uma vez que a identidade é um processo de construção que pressupõe negociações com o mundo externo.

Trata-se de levar em conta a negociação dos Cinta Larga com esferas da sociedade não indígena, que, por sua vez, é influenciada por códigos, leis e tendências humanistas que preconiza cada dia mais a constituição de uma sociedade pluralista em que as diferenças devem ser respeitadas. Isso significa que, embora eles sejam estigmatizados pela população local de um lado, de outro, existe um aparo legal e uma tendência humanista, à qual os indígenas recorrem inclusive para se afirmarem nesse cenário. O O t r o ponto interessante a ser salientado no discurso do representante indígena é que existe uma lógica Cinta Larga para a exploração dos diamantes na mina: "Não que nós queremos explorá-la até que não reste nada nela, mas explorá-la quando precisamos" (Chefe Pio). Essa lógica aponta para uma exploração que, ao invés de ser um movimento para os valores ocidentais capitalistas, obedece a uma dinâmica própria em que a exploração só é permitida mediante a necessidade, e não no interesse genuinamente capitalista de acúmulo de riquezas.

Já no discurso do Representante da Funai, encontra-se uma visão romantizada em relação ao índio, pois ele entende que são os brancos que facilitam a aquisição de bens aos índios. Nessa perspectiva, a pureza desse grupo seria afetada pela perversidade de não índios. Esse ator social faz uma representação da representação já existente dos índios em relação à população local ao rebater que, ao contrário da imagem que se tem do índio como estranho, preguiçoso, perigoso, os Cinta Larga são pessoas calmas, dóceis e gentis.

O argumento encontrado por este representante para o assassinato dos garimpeiros se baseia numa frase que ele já ouviu de um Cinta Larga: "Se você passar perto de uma colméia, as abelhas não farão nada a você, mas se você tentar levar algo de dentro dela, elas o atacarão”. A justificativa para o massacre é, então, uma atitude de defesa, e não sinônimo de agressividade.

Diante da ingenuidade atribuída aos indígenas Cinta Larga, tal representante acredita ainda que a exploração da jazida traria para os índios efeitos iníquos, pois acarretaria na perda da identidade e da cultura indígena. A identidade, nesse prisma, é algo estático e que não permite (re) elaborações. Explorar diamantes, inserir a lógica da permuta, do lucro, o hibridismo, portanto, é enxergado como aculturação.

Já a ótica do representante dos garimpeiros é marcada pelo interesse em explorar a jazida. Frente à ameaça latente de que a exploração da mina fique a cargo dos Cinta Larga, a representação construída pelo representante dos garimpeiros é percebida no momento em que este assevera que a mina pertence aos brasileiros, indicando, portanto, que índios não seriam brasileiros.

Por fim, cabe considerar o discurso do Representante da Polícia Federal, que considera esta uma causa maior do que o simples embate entre garimpeiros e índios, indicando a existência de interesses dos cartéis na especulação em relação ao Mercado de diamantes. A representação construída por esse ator social diz respeito à pobreza que iguala 
garimpeiros e indígenas, podendo ser percebida na oração: "é uma guerra de miseráveis".

A miséria, através desse discurso, é tratada como o alimento do embate. $\mathrm{O}$ embate não tira os "guerreiros" da condição de miseráveis. É, na verdade, um artifício para que os cartéis das empresas mineradoras sejam camuflados. Essa representação está intimamente relacionada à instituição da qual ele faz parte, a Polícia Federal, que o impele a investigar o que tem por trás do conflito.

\section{CONSIDERAÇÕES FINAIS}

As discussões aqui propostas em torno da exploração de diamantes da Reserva Roosevelt permitem perceber que a Identidade dos Grupos pode ser construída e desconstruída a todo o momento. A própria situação do conflito propicia a (re) significação de determinada cultura e tende a trazer em volta de si uma polarização de posicionamentos e uma mobilidade de discurso, pois os atores sociais não trazem simplesmente uma opinião individual, mas as causas das instituições que representam ou do grupo social do qual fazem parte. Nesse sentido, são válidas as proposições de BARTH (1998) e OLIVEIRA(1972), no sentido de que as interações entre sujeitos podem gerar transformações que modelam a identidade, sendo que a identidade deve ser vista como algo dinâmico e também passível de mudanças.

Por essa perspectiva, o fator étnico não é colocado em questionamento, sendo autêntico o movimento dos Cinta Larga em direção ao bens, à cidade e às coisas a que ele remete. Isso tão somente aponta para um novo processo social que, por sua vez, implica o movimento da identidade

No caso analisado, percebeu-se que a não correspondência a um estigma pode culminar em outro, como foi o que ocorreu quando a população local, ao compreender que os índios não mais correspondiam ao pré-estabelecido (selvagem, isolado, rudimentar), passa a estigmatizá-los como assassinos impunes, privilegiados pela esfera governamental e pelas leis vigentes no país.

Ainda vale considerar que o próprio grupo tradicional oscila no discurso ao se auto-representar. Ora é conveniente que sejam estigmatizados como caçadores-selvagem, ora apresentam em seus discursos uma autonomia no sentido de estarem aptos a explorarem os diamantes através de uma companhia indígena. Isso se dá pela possibilidade, preconizada por TURNER (1974), qual seja de transitar entre dois mundos. De um lado, o universo indígena e, de outro, o mundo dos não índios, que não se posiciona de forma homogênea em relação a essa questão. Isso pode ser verificado pela estigmatização que os indígenas Cinta Larga vivenciam em relação à população local, mas também na auto afirmação, enquanto grupo, através dos discursos humanistas que valorizam a pluralidade.

Um ponto fundamental nesta análise foi perceber que existe uma lógica Cinta Larga para a exploração dos diamantes, a qual difere da lógica da permuta, barganha e acumulação de riqueza, mas é uma lógica que obedece a uma necessidade cujos atributos retomam elementos já cultivados pelos grupos indígenas. Desse modo, como a caça é importante para satisfazer uma necessidade fisiológica (a saciedade da fome), a exploração de diamantes supre uma nova necessidade que abrange a incorporação de bens materiais. Nesse sentido, percebe-se uma junção de valores, mas que não necessariamente implicaria aculturação, mas um processo de (re) significação.

\section{REFERÊNCIAS}

BACZKO, B. Imaginação social. In: Enciclopédia Einaudi. Lisboa: Imprensa Nacional/ Casa da Moeda, 1985. V.5.

BARTH, F. Grupos étnicos e suas fronteiras. In: POUTIGNAT, P. Teorias da etnicidade. Seguido de grupos étnicos e suas fronteiras de Fredrik Barth, Philippe Poutignat, Jocelyne Streiff-Fenard. Tradução de Elcio Fernandes. São Paulo: UNESP, 1998. 130p.

FERREIRA NETO, J.A.; DOULA, S.M. Assentamentos rurais organização, mobilização e imaginário Social. Visconde do Rio Branco: Suprema, 2003. 118p.

FRONTLINE/WORLD. Brazil Jewel of the Amazon: the conflict over Brazil`s diamond. AIRS ON PBS. Disponível em: <http:// www.pbs.org/frontlinewold/stories/brasil501/.Boston>. Acesso em: 17 abr. 2009.

FOUCAULT, M. A ordem do discurso. 5.ed. São Paulo: Loyola, 1996. 79p.

GOFFMAN, E.. Estigma - notas sobre manipulação da identidade deteriorada. Rio de Janeiro: Zahar, 1982. 172p.

GORDON, C. Economia selvagem: ritual e mercadoria entre os índios. São Paulo: UNESP: ISA; Rio de Janeiro: NUTI, 2006. 252p.

OLIVEIRA, R.C. de. "Problemas relativos à fricção interétnica”. In: OLIVEIRA, R. C. A Sociologia do Brasil Indígena. Rio de Janeiro: Tempo Brasileiro; Brasília: Editora da UNB. (1972) 1978. 222p.

SOUZA, J. A construção social da subcidadania. Para uma sociologia política da modernidade periférica. Belo Horizonte/Rio de Janeiro: UFMG e Iuperj, 2003. 207p.

TURNER, V. O processo ritual: estrutura e anti-estrutura. Petrópolis: Vozes, 1974. [1969]. 248p. 